\title{
Effect of Intravenous Lipid Emulsion on Clozapine Acute Toxicity in Rats
}

\author{
Bahareh Sadat Yousefsani ${ }^{1}, 2$, Seyed Ahmad Mohajeri ${ }^{3}$, Mohammad Moshiri ${ }^{3}$, \\ Amir Hossein Jafarian', Hossein Hosseinzadeh ${ }^{3,5 *}$ \\ ${ }^{1}$ Research Institute for Islamic and Complementary Medicine, Iran University of Medical Sciences, Tehran, Iran \\ ${ }^{2}$ School of Persian Medicine, Iran University of Medical Sciences, Tehran, Iran \\ ${ }^{3}$ Department of Pharmacodynamy and Toxicology, School of Pharmacy, Mashhad University of Medical Sciences, Mashhad, Iran \\ ${ }^{4}$ Cancer Molecular Pathology Research Center, Ghaem Hospital, Faculty of Medicine, Mashhad University of Medical Sciences, Mashhad, Iran \\ ${ }^{5}$ Pharmaceutical Research Center, Pharmaceutical Technology Institute, Mashhad University of Medical Sciences, Mashhad, Iran
}

\section{Key Words}

Clozapine, Intravenous Lipid Emulsion (ILE), acute toxicity, antidote, pathologic signs.

\begin{abstract}
Objectives: Many studies have been reported the efficacy of intravenous lipid emulsion (ILE) as an antidote on acute lipophilic drug toxicity. Clozapine, highly lipophilic dibenzodiazepine neuroleptics, is an important medication in the schizophrenia therapy regimen. Acute intoxication with antipsychotics is one of the main reasons for the referral of poisoned patients to the hospital. We expected that ILE could be used for the therapy of acute clozapine intoxicated patients.
\end{abstract}

Methods: We used two groups of consisting of six male rats. Both groups received a toxic dose of clozapine (40 $\mathrm{mg} / \mathrm{kg}$ ) intravenously, via the tail vein. After 15 minutes, they were treated with intravenous infusion of $18.6 \mathrm{mg} /$ $\mathrm{kg}$ normal saline (NS group), or $18.6 \mathrm{mg} / \mathrm{kg}$ ILE $20 \%$ (ILE group). We evaluated blood pressure (BP) and heart rate by power lab apparatus through the tail artery, ataxia by a rat rotary circle, seizure scores and death in multiple times after starting clozapine administration. For bio-

Received: Feb 02, 2019 Reviewed: Apr 15, 2019 Accepted: May 31, 2019

(c) This is an Open-Access article distributed under the terms of the Creative Common Attribution Non-Commercial License (http://creativecommons.org/licenses/by-nc/4.0/) which permits unrestricted noncommercial use, distribution, and reproduction in any medium, provided the original work is properly cited.

@ This paper meets the requirements of KS X ISO 9706, ISO 9706-1994 and ANSI/NISO Z39.48-1992 (Permanence of Paper). chemical and pathological evaluations the samples of tissue and blood were taken.

Results: Our results demonstrated that ILE $20 \%$ could return hypotension-induced clozapine better than normal saline. Furthermore, ataxia and seizure have rectified more rapidly and deaths reduced. Clozapine administration causes pancreatitis and lung injury but fat emulsion did not show an optimal effect on tissue damages caused by clozapine toxicity.

Conclusion: In conclusion, ILE can remove toxic signs of clozapine same as other lipophilic medicines, however, clinical uses of ILE for this intention requires more appraisement to determine the precise implication and safety.

\section{Introduction}

AILE has been used to supply calories in the form of free fatty acids in patients who require parenteral nutrition. There are many reports on the efficacy of intravenous lipid emulsion (ILE) as an antidotal candidate in intoxication with medications [1-3]. Investigations and case reports about this novel benefit of ILE result in adding it into Guidelines for the Management of Severe Local Anesthetic Toxicity [4-6]. ILE has been shown to have positive impacts toxicity resulted in lipophilic drugs overdose through some case reports 
and animal studies $[7,8]$. Acute antipsychotic drug poisoning is one of the most important reasons for referring to the hospital $[9,10]$. Clozapine, highly lipophilic dibenzodiazepine neuroleptics, is one of the most effective for the therapy of schizophrenia and is increasingly being used to treat affective disorders, some neurological disorders, and aggression $[11,12]$. Clozapine toxicity has been commonly seen in psychotic patients [13, 14], especially in patients who received different drugs simultaneously [13, 15].

Clozapine toxicity like other antipsychotic toxicity causes side effects in several organ systems that need emergency evaluation and treatment, like serious cardiovascular side effects include hypotension and myocarditis; the serious neurological side effects include seizures and ataxia; serious hematological side effect of agranulocytosis and tissue injuries [16-22]

The primary objective of this study is to determine if ILE would have beneficial effects in the setting of clozapine toxicity.

\section{Materials and Methods:}

\subsection{Animals}

Adult male Wistar rats (Bu-Ali Research Institute, Mashhad, I.R. Iran), weighing 250-300 g, were used for all experiments. These animals were housed in a pathogen-free facility on a 12 hour light/dark schedule and with ad lib access to food and water. All animal procedures were approved by the ethics committee of MUMS (Mashhad University of Medical Sciences).

\subsection{Preparation of clozapine intravenous solution}

$5 \mathrm{mg}$ of the clozapine powder (Exir Pharmaceutical Co., Iran) dissolved in $\mathrm{HCl}$ for preparing the clozapine intravenous (IV) solution. Then, normal saline was used for reaching working concentration. The neutralization was done with $\mathrm{NaCl}$ solution [23]. The sterile pyrpgen free normal saline (NS) and ILE (Fresenius Kabi AB, Spain) were also IV administered.

\subsection{Procedures}

\subsubsection{Animal Groups}

We used two groups of consisting six male rats. Both groups received a toxic dose of clozapine, $40 \mathrm{mg} / \mathrm{kg}$ intravenously, through tail vein through 60 seconds (time 0 ). After 15 minutes (time 1) the first group received $18.6 \mathrm{mg} /$ $\mathrm{kg}$ normal saline intravenously (NS group), and the second group received $18.6 \mathrm{mg} / \mathrm{kg}$ ILE $20 \%$ intravenously (ILE group) [24].

\subsubsection{Animal Toxicity Tests}

All toxicological evaluations and survival observations were performed at $0,15,30,45,60,180,360,720$ and 1440 minutes after starting clozapine administration.

\subsubsection{Evaluation of cardiovascular toxicity, blood pressure, and heart rate measurement}

Blood pressure (BP) and heart rate were evaluated by power lab apparatus (Data Acquisition Systems, US) through the tail artery, in the conscious animals. For this purpose, rats were restricted in the clear restraint tube. Their tails were warming up to $28-29^{\circ} \mathrm{C}$. After allowing 15 min for each animal to acclimatize in the tube, an 11-mm cuff was placed around the tail. The pulses were recorded at a rate of $3 \mathrm{~mm} \mathrm{Hg} / \mathrm{s}$. The systolic pressure was incorporated as the pressure at the point when the first tail pulse was discovered. By calculating the number of pulses registering over a 2-s period, the heart rate was calculated (beats/min). [25].

\subsection{Evaluation of neurotoxicity, ataxia, and seizure}

\subsubsection{Rotarod performance}

Rotarod test (Borj Sanat, Iran), as ataxic criteria, measured the ability of the animal to maintain itself on the revolving rod. Four days before the onset of tests, the rats were trained (three 2-min trials/day). Only animals able for remaining 120 seconds on the rod without any fall, were selected for experiments [26].

\subsubsection{Seizure scores}

Seizure scores were classified according to a modified scale [27].

\subsection{Biochemical and Histopathological Studies}

For biochemical and pathological evaluations the samples of tissue and blood were taken from all animals after $24 \mathrm{~h}$ or at the death point. All tests were blindly carried out with a single pathologist.

\subsection{Statistical Analysis:}

Statistical analysis of all variables was performed using Statistical Package for Social Sciences software version 11.5 (SPSS Inc., Chicago, Illinois, USA). Two-way repeated measures analysis of variance (ANOVA) was used to evaluate the differences in BP of different groups. Kruskal-Wallis ANOVA or Mann-Whitney test was used, if necessary. The alpha level was set at 0.05 .

\section{Results}

\subsection{Survival}

After Clozapine administration, animals were assessed for their survival and 2 deaths were recorded in the NS group before 24 hours.

According to Fisher Exact test, there were no significant differences with regard to the number of deaths between the 2 groups receiving either NS or ILE. $(\mathrm{P}=0.4545)$ 


\subsection{Seizur}

According to seizure assessment, seizure scores during a 24-hour observation were recorded. Seizures initiated as soon as Clozapine injection was completed in all groups. ILE significantly decreased $(\mathrm{P}<0.05)$ seizure scores in comparison with NS (Fig. 1).

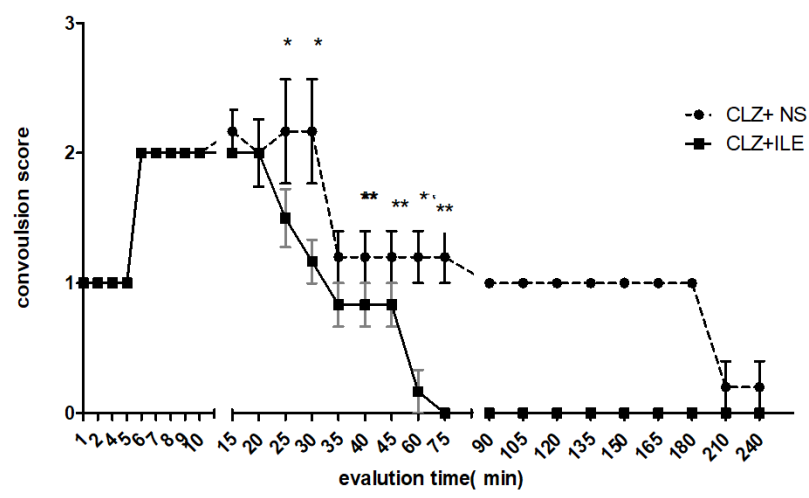

Figure 1 Effect of infusion of $18.6 \mathrm{ml} / \mathrm{kg}$ intravenous lipid emulsion (ILE) on seizure scores induced by acute clozapine (40 mg/ $\mathrm{kg}$ ) poisoning in comparing with normal saline (NS). ${ }^{*} \mathrm{P}<0.5$, ** $\mathrm{P}<0.01$ data were reported by Mean $\pm \mathrm{SE}$, analyzed by ANOVA, post test $=$ Tuky, $(\mathrm{N}=6)$

\subsection{Ataxia}

ILE significantly rectified ataxia more rapid than NS, and ILE treated rats were able to stay and walk on the rat rotarod at the 3rd hour $(\mathrm{P}<0.01)$, however, the NS-treated group was ataxic more than 24 hours (Fig. 2).

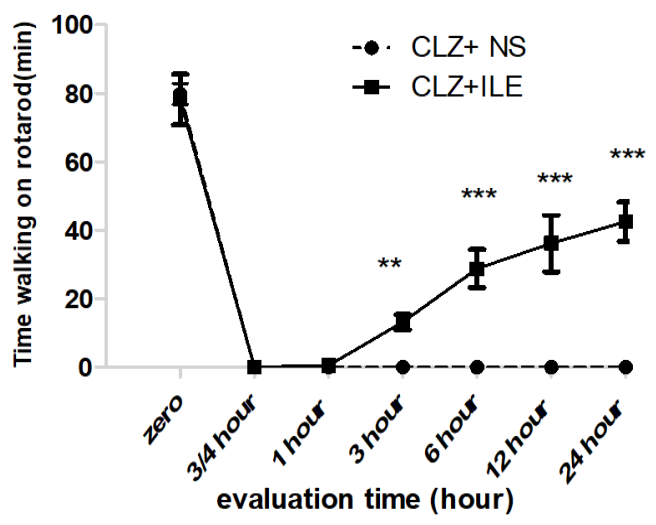

Figure 2 Effect of infusion of $18.6 \mathrm{ml} / \mathrm{kg}$ intravenous lipid emulsion (ILE) on acute clozapine $(40 \mathrm{mg} / \mathrm{kg})$ induced an ataxia in comparing with normal salin (NS).** $(\mathrm{p}<0.01){ }^{* * *}=(\mathrm{p}<0.001)$ data were reported by Mean \pm SE, analyzed by ANOVA, post test $=$ Tuky, $(\mathrm{N}=6)$

\subsection{Blood pressure}

As shown in figure 3, administration of $18.5 \mathrm{ml} / \mathrm{kg}$ of NS or ILE to clozapine poisoned hypotensive rats raised their blood pressure to near normal baseline, but NS-treat- ed group become hypotensive again, while the BP of ILE treated group remained near normal up to the end of measurement $(\mathrm{P}<0.001)$.

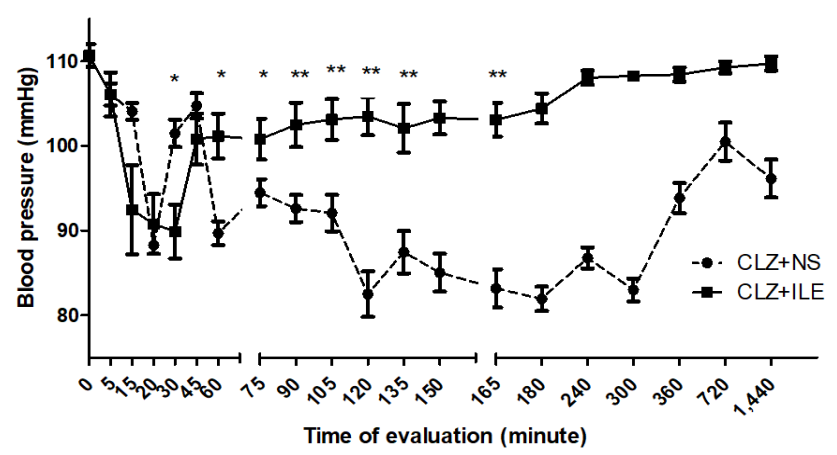

Figure 3 Effect of lipid emulsion on blood pressure after acute clozapine poisoning in different groups of animals. Significant difference $^{*}=(\mathrm{P}<0.05),{ }^{* *}=(\mathrm{p}<0.01){ }^{* * *}=(\mathrm{p}<0.001),(\mathrm{N}=6)$

\subsection{Histopathological Studies}

The histopathological evaluation of the lung of the rats showed similar educative secretions and alveolar wall Inflammation in both groups (Fig. 4). However, the conjugation of vessels and fat necrosis of pancreatic tissue slides were reported equal in both groups, the scoring of pancreatic parenchyma inflammation in ILE group was lower than NS treated group $(1 \pm 0.089$ and $1.67 \pm 0.51 ; \mathrm{P}<0.05)$ (Fig. 5).

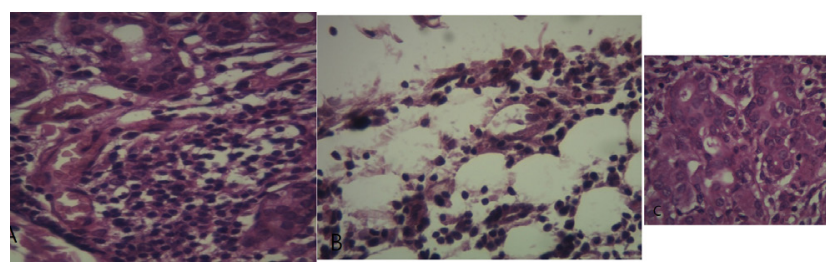

Figure 4 Pancreas slides of rats treated by Clozapine and intravenous lipid emulsion (ILE) or normal saline (NS). Magnification $=\times 400$. (A) Moderate inflammation: Clozapine + NS (B) Sever inflammation: Clozapine+NS. (C) Mild inflammation: Clozpine+ILE , $(\mathrm{N}=6)$

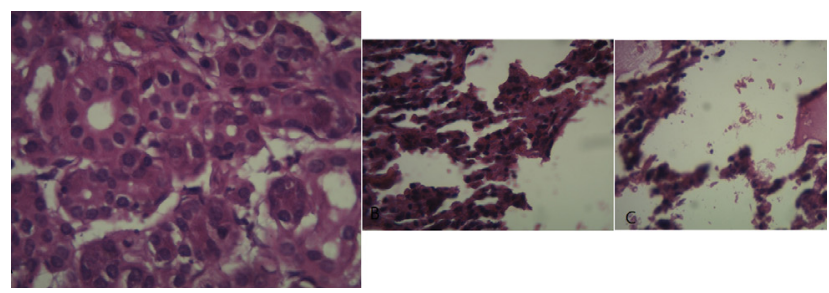

Figure 5 Lung slides of rats treated by Clozapine and intravenous lipid emulsion (ILE) or normal saline (NS). (A) Magnification = $\times 400$, Inflammation of the lining of the lung alveoli in both groups (Clozapine+NS and Clozapine+ILE). (B) Magnification $=\times 100$ Pulmonary alveolar wall with hemorrhage, inflammation and vessels Conjugated in both groups (clozapine+NS and Clozapine+ILE). (C) Magnification $=\times 100$ Exudative secretions and edematous wall of the alveoli in both groups (Clozapine+NS and Clozapine+ILE). 


\subsection{Biochemical tests}

As demonstrated in table 1, following clozapine intoxication, lipase and amylase increased in both groups, and there was no significant difference between the NS group and the ILE group in the amount of the amylase and lipase. The number of blood platelets and white blood cell in rats receiving NS compared with ILE after clozapine intoxication significantly reduced $(\mathrm{P}<0.001)$. Other cell count criteria were almost similar in both groups.

Table 1 The result of comparing the biochemical tests in both groups receiving normal saline or intralipid after clozapine poisoning. (Significant difference ${ }^{*}$ : $\mathrm{P}<0.05$ )

\begin{tabular}{|c|c|c|}
\hline Laboratory Tests & $\mathrm{CLZ}+\mathrm{NS}$ & CLZ + ILE \\
\hline Lipase U/L & $254 \pm 0.52$ & $248 \pm 0.44$ \\
\hline Amylase U/L & $2744.8 \pm 104.26$ & $2276.5 \pm 205.12$ \\
\hline WBC/103 $\mu \mathrm{I}$ & $8.1097 \pm 0.319$ & $11.458 \pm 0.5^{*}$ \\
\hline $\mathrm{RBC} / \mathbf{1 0 3} \mu \mathrm{l}$ & $7.313 \pm 6.2582$ & $7.568 \pm 0.1848$ \\
\hline PLT/103 $\mu \mathrm{l}$ & $390 \pm 5.164$ & $687 \pm 17.860 *$ \\
\hline
\end{tabular}

\section{Discussion}

As the result revealed fat emulsion could reduce toxic signs of clozapine same as other lipophilic medicines.

After clozapine administration, animals were assessed for survival and 2 deaths were recorded in the NS group during the 24 hours evaluation. Although the mortality rate of ILE treated group was lower than NS, there was no significant difference between the two groups, and it may be due to small sample size. Therefore, further study is needed to evaluate the effects of ILE on clozapine mortality.

Using plasma expanders is an effective way for the treatment of clozapine-induced hypotension. In our investigation, clozapine-induced hypotension has responded to a volume expander solution like normal saline. Normal saline could raise reduced BP of rats after administration, although its effect was not long-lasting and BP reduced again at the first hour (Fig.3). A persistent rise in BP after ILE administration suggests that it may also act through mechanisms other than volume expansion. It seems that ILE could redistribute clozapine, which is a high lipid soluble medicine from peripheral or central receptors into the new neutral compartment and resolves the signs of toxicity. Previous animal tests support the effect of ILE in reveling lipophilic drugs induced hypotension. In a study ILE has shown significant positive effects for primary or secondary hemodynamic endpoints in metoprolol, verapamil, tramadol and haloperidol intoxication [2, 7, 28-30]. There is a suggested mechanism for ILE in revealing drugs-induced hypotension, the lipid sink theory. Through lipid sink theory, lipophilic drugs redistribute from the site of toxicity into a new lipid compartment following ILE infusion. Lipid sink theory justifies the failure of ILE to improve intoxication of less lipid-soluble drugs such as nifedipine [31]. Clozapine volume of distribution is lower than that of other antipsychotic drugs, but, is nonetheless considerable (2.0 $-5.1 \mathrm{~L} / \mathrm{kg}$ ) [32].

Although the lipid sink theory could explain the antihypotensive effect of ILE in lipophilic drug toxicity, it is suggested that there are other important mechanisms. Free fatty acids increase the calcium influx into myocytes and smooth muscles [33]. It not only improves impaired cardiac function but also raises blood pressure [34, 35]. Although we did not evaluate the cardiac function of intoxicated rats, it is possible that some of the antidotal effects of ILE on resolving clozapine-induced hypotension are related to its cardiac effects, as well.

The toxic level of clozapine causes neurotoxicity symptoms, such as ataxia and seizure. In addition to blocking dopamine receptors, clozapine antagonizes a number of other receptor sites, including the norepinephrine, histamine, acetylcholine and serotonin system and partially reverses the inhibitory effect of GABA on 35S-t-butyl bicycle phosphorothionate (35S-TBPS) binding [36]. According to previous studies, clozapine affects excitatory amino acid release in nucleus accumbens [37], alters glutamate-dependent excitatory postsynaptic potentials in hippocampal slices [38] and glutamate- mediated evoked field potentials in rat striatum [39]. Clozapine-induced ataxia may relate to its serotonergic effect [40]. However, clozapine administration induced ataxia and some levels of the seizure (time 0 ), at time 1 these signs have rectified more rapidly in the ILE group than in the NS group. The most important hypothesis that explains the mechanism of the antidotal effect of ILE against CNS intoxication of xenobiotics is the lipid sink theory [31]. It suggests that lipophilic medicines or xenobiotics, when administered at toxic levels, were redistributed from their site of action to a new inner compartment made by ILE in the vessels. Also, there is another antidotal mechanism for ILE in neurotoxicity caused by clozapine, ILE and high chain free fatty acid are capable of increasing intracellular calcium concentrations in neurons, and also in ventricular muscles cells. Thus, it is suggested that ILE not only reduces clozapine concentration in target organs based on the lipid sink theory but also restores the clozapine-induced neurotoxicity through increasing the intraneuronal calcium concentration.

Most patients who take clozapine, especially in the first month of use, symptoms of inflammation of the pancreas and increasing enzymes like amylase and lipase are visible [41]. In this study after pathological tests, pancreatitis was observed in both groups receiving normal saline and ILE after clozapine intoxication, but the parenchymal inflammation of pancreas tissue was significantly higher in the NS group compare with the ILE group. But other pathological factors explored in the study did not show a significant difference between the two groups. On the other hand, there were no significant differences in the amount of amylase and lipase in both groups.

One of the important body organ that clozapine was stored and causes toxicity is the lungs [42]. In this study, ILE also neither reduce nor raised clozapine intoxication lung injuries. Perhaps no decrease in lung injury is due to the fat emulsion potential to cause pulmonary injury [43]. 
Therefore, we can conclude that these results represent the little effect of ILE in resolving tissue damages caused by clozapine toxicity.

Jagadheesan, et al., in a study showed that $17.8 \%$ of clozapine-treated people at least once affected with thrombocytopenia or a reduction in the number of platelets [44]. Administration of clozapine can cause drug-induced leukopenia and neutropenia, especially in the patient with low WBC or Co- administration with other medicines [4549]. In this study, platelet and leukocyte count of NS-treated group significantly was lower than ILE-treated group, which reflects the ability of ILE to prevent of clozapine-induced leukopenia and neutropenia.

\section{Conclusion}

In conclusion, ILE can remove toxic signs of clozapine as same as other lipophilic medicines. But ILE has little effect in relieving tissue damage induced by clozapine. However, clinical uses of ILE for this purpose needs more evaluation to determine the exact indication and safety.

\section{Conflict of Interest}

The authors declare that there are no conflicts of interest.

\section{Acknowledgement}

The authors are thankful to the Vice Chancellor of Research, Mashhad University of Medical Sciences for financial support.

\section{References}

1. Aksel G, Guneysel O, Tasyurek T, Kozan E, Cevik SE. Intravenous Lipid Emulsion Therapy for Acute Synthetic Cannabinoid Intoxication: Clinical Experience in Four Cases. Case reports in emergency medicine. 2015;2015180921.

2. Barton CA, Johnson NB, Mah ND, Beauchamp G, Hendrickson R. Successful treatment of a massive metoprolol overdose using intravenous lipid emulsion and hyperinsulinemia/euglycemia therapy. Pharmacotherapy. 2015;35(5):e56-60.

3. Herring JM, McMichael MA, Corsi R, Wurlod V. Intravenous lipid emulsion therapy in three cases of canine naproxen overdose. J Vet Emerg Crit Care (San Antonio).2015.

4. Brull SJ. Lipid emulsion for the treatment of local anesthetic toxicity: patient safety implications. Anesthesia and analgesia. 2008;106(5):1337-9.

5. Burch MS, McAllister RK, Meyer TA. Treatment of local-anesthetic toxicity with lipid emulsion therapy. American journal of health-system pharmacy : AJHP : official journal of the American Society of Health-System Pharmacists. 2011;68(2): 125-9.

6. Cave G, Harvey M. Intravenous lipid emulsion as antidote beyond local anesthetic toxicity: a systematic review. Academic emergency medicine : official journal of the Society for Academic Emergency Medicine. 2009;16(9):815-24.

7. Moshiri M, Vahabzadeh M, Mohammadpour AH, Hosseinzadeh $\mathrm{H}$. Evaluation of intravenous lipid emulsion on haloperidol-induced hypotension in rabbits. Toxicology and industrial health. 2014.

8. Fettiplace MR, Pichurko A, Ripper R, Lin B, Kowal K, Lis K, Schwartz D, Feinstein DL, Rubinstein I, Weinberg G. Cardiac depression induced by cocaine or cocaethylene is alleviated by lipid emulsion more effectively than by sulfobutylether-beta-cyclodextrin. Academic emergency medicine : official journal of the Society for Academic Emergency Medicine. 2015;22(5):508-17.

9. Khlifi M, Zun L, Johnson G, Harbison R. Etiological characterization of acute poisonings in the emergency department. J Emerg Trauma Shock. 2009;2(3):159-63.

10. Doak MW, Nixon AC, Lupton DJ, Waring WS. Self-poisoning in older adults: patterns of drug ingestion and clinical outcomes. Age Ageing. 2009;38(4):407-11.

11. Dassa D, Kaladjian A, Azorin JM, Giudicelli S. Clozapine in the treatment of psychotic refractory depression. Br J Psychiatry. 1993;163822-4.

12. Sajatovic M, Ramirez LF, Kenny JT, Meltzer HY. The use of clozapine in borderline-intellectual- functioning and mentally retarded schizophrenic patients. Compr Psychiatry. 1994;35(1):29-33.

13. Cadeddu G, Deidda A, Stochino ME, Velluti N, Burrai C, Del Zompo M. Clozapine toxicity due to a multiple drug interaction: a case report. Journal of medical case reports. 2015;977.

14. Matthews CJ, Hall TL. A clozapine conundrum: clozapine toxicity in an acute medical illness. Australasian psychiatry : bulletin of Royal Australian and New Zealand College of Psychiatrists. 2014;22(6):543-5.

15. Szymanski S, Lieberman JA, Picou D, Masiar S, Cooper 
T. A case report of cimetidine-induced clozapine toxicity. The Journal of clinical psychiatry. 1991;52(1):21-2.

16. Tueth MJ. Emergencies caused by side effects of psychiatric medications. Am J Emerg Med. 1994;12(2):212-6.

17. Hawkins DJ, Unwin P. Paradoxical and severe hypotension in response to adrenaline infusions in massive quetiapine overdose. Crit Care Resusc. 2008;10(4):320-2.

18. Bhatia MS, Gupta R, Dhawan J. Myocarditis after overdose of conventional antipsychotics. World J Biol Psychiatry. 2009;10(4 Pt 2):606-8.

19. Aboueid L, Toteja N. Clozapine-Induced Myocarditis: A Case Report of an Adolescent Boy with Intellectual Disability. Case reports in psychiatry. 2015;2015482375.

20. Lee SH, Yang YY. Reversible neurotoxicity induced by a combination of clozapine and lithium: a case report. Zhonghua Yi Xue Za Zhi (Taipei). 1999;62(3):184-7.

21. Huang CH, Fu SH, Hsu S, Huang YY, Chen ST, Hsu BR. High-fat diet aggravates islet beta-cell toxicity in mice treated with clozapine. Chang Gung Med J. 2012;35(4):318-22.

22. Flanagan RJ. Side effects of clozapine and some other psychoactive drugs. Curr Drug Saf. 2008;3(2):115-22.

23. Scorza MC, Castane A, Bortolozzi A, Artigas F. Clozapine does not require 5-HT1A receptors to block the locomotor hyperactivity induced by MK-801 Clz and MK-801 in KO1A mice. Neuropharmacology. 2010;59(1-2):112-20.

24. Weinberg G, Ripper R, Feinstein DL, Hoffman W. Lipid emulsion infusion rescues dogs from bupivacaine-induced cardiac toxicity. Region Anesth Pain M. 2003;28(3):198-202.

25. Bunag RD. Validation in awake rats of a tail-cuff method for measuring systolic pressure. J Appl Physiol. 1973;34(2):279-82.

26. Joksimovic S, Varagic Z, Kovacevic J, Van Linn M, Milic M, Rallapalli S, et al. Insights into functional pharmacology of alpha(1) GABA(A) receptors: how much does partial activation at the benzodiazepine site matter? Psychopharmacology (Berl). 2013;230(1):113-23.

27. Vafaee F, Hosseini M, Hassanzadeh Z, Edalatmanesh MA, Sadeghnia HR, Seghatoleslam M, et al. The Effects of Nigella Sativa Hydro-alcoholic Extract on Memory and Brain Tissues Oxidative Damage after Repeated Seizures in Rats. Iran J Pharm Res. 2015;14(2):547-57.

28. Moshiri M, Mohammadpour AH, Vahabzadeh M, Etemad L, Memar B, Hosseinzadeh H. Evaluating the effects and safety of intravenous lipid emulsion on haloperidol-induced neurotoxicity in rabbit. BioMed research international. 2014;2014949262.

29. Vahabzadeh M, Moshiri M, Mohammadpour AH, Hosseinzadeh H. Promising effects of intravenous lipid emulsion as an antidote in acute tramadol poisoning. Region Anesth Pain M. 2013;38(5):425-30.

30. Sampson CS, Bedy SM. Lipid emulsion therapy given intraosseously in massive verapamil overdose. Am J Emerg Med. 2015.

31. Eren Cevik S, Tasyurek T, Guneysel O. Intralipid emulsion treatment as an antidote in lipophilic drug intoxications. Am J Emerg Med. 2014;32(9):1103-8.

32. Coward DM. General pharmacology of clozapine. Br J Psychiatry Suppl. 1992;(17):5-11.
33. Rothschild L, Bern S, Oswald S, Weinberg G. Intravenous lipid emulsion in clinical toxicology. Scand J Trauma Resusc Emerg Med. 2010;1851.

34. Clark MK. Lipid emulsion as rescue for local anesthetic-related cardiotoxicity. J Perianesth Nurs. 2008;23(2):111-7; quiz 8-21.

35. Litz RJ, Roessel T, Heller AR, Stehr SN. Reversal of central nervous system and cardiac toxicity after local anesthetic intoxication by lipid emulsion injection. Anesthesia and analgesia. 2008;106(5):1575-7, table of contents.

36. Squires RF, Saederup E. A review of evidence for GABergic predominance/glutamatergic deficit as a common etiological factor in both schizophrenia and affective psychoses: more support for a continuum hypothesis of "functional" psychosis. Neurochem Res. 1991;16(10):1099-111.

37. Miller JW, Gray BC, Turner GM, Bardgett ME. An ascending seizure-controlling pathway in the medial brainstem and thalamus. Exp Neurol. 1993;121(1):106-12.

38. Baskys A, Wang S, Remington G, Wojtowicz JM. Haloperidol and loxapine but not clozapine increase synaptic responses in the hippocampus. European Journal of Pharmacology. 1993;235(2-3):305-7.

39. Lidsky TI, Yablonsky-Alter E, Zuck L, Banerjee SP. Anti-glutamatergic effects of clozapine. Neurosci Lett. 1993;163(2):155-8.

40. Park WK, Jeong D, Cho H, Lee SJ, Cha MY, Pae AN, et al. KKHA-761, a potent D3 receptor antagonist with high 5-HT1A receptor affinity, exhibits antipsychotic properties in animal models of schizophrenia. Pharmacol Biochem Behav. 2005;82(2):361-72.

41. Raja M, Azzoni A. A Case of Clozapine-Associated Pancreatitis. The Open Neuropsychopharmacology Journal. 2011;45-7.

42. Gardiner TH, Lewis JM, Shore PA. Distribution of clozapine in the rat: localization in lung. The Journal of pharmacology and experimental therapeutics. 1978;206(1):151-7.

43. Aksnes J, Eide TJ, Nordstrand K. Lipid entrapment and cellular changes in the rat myocard, lung and liver after long-term parenteral nutrition with lipid emulsion. A light microscopic and ultrastructural study. APMIS : acta pathologica, microbiologica, et immunologica Scandinavica. 1996;104(7-8):515-22.

44. Jagadheesan K, Agarwal S, Nizamie HS. Clozapine-induced Thrombocytopenia: a Pilot Study. Hong Kong J Psychiat. 2003;13(2):12-5.

45. Aydin M, Ilhan BC, Calisir S, Yildirim S, Eren I. Continuing clozapine treatment with lithium in schizophrenic patients with neutropenia or leukopenia: brief review of literature with case reports. Therapeutic advances in psychopharmacology. 2016;6(1):33-8.

46. Grover S, Hegde A, Agarwal M, Sachdeva MS. Olanzapine-associated leukopenia and thrombocytopenia managed with lithium in a patient who developed leukopenia with clozapine in the past: a case report. The primary care companion for CNS disorders. 2012;14(6).

47. Bogers JP, Cohen D, Schulte PF, van Dijk D, Bakker B. Clozapine-induced leukopenia: arguments for rechallenge. Irish journal of medical science. 2012;181(1):155-6. 
48. Latif Z, Malik MA, Jabbar F, Ahmed Y, McDonough C. Clozapine-induced late leukopenia. Irish journal of medical science. 2012;181(1):139-41.

49. Charbonneau K, Landry P. Leukopenia and neutropenia after intoxication with diphenhydramine (Nytol) during clozapine treatment. Journal of clinical psychopharmacology. 2008;28(6): 706-7. 